\title{
Angiopoietin-like protein 2 mediates endotoxin-induced acute inflammation in the eye
}

\author{
Atsuhiro Kanda ${ }^{1}$, Kousuke Noda ${ }^{1}$, Yuichi Oike ${ }^{2}$ and Susumu Ishida ${ }^{1}$
}

Angiopoietin-like protein (Angptl) 2 is a key mediator linking obesity to chronic adipose-tissue inflammation and systemic insulin resistance, and increasing evidence has shown that Angpt/2 is associated with various chronic inflammatory diseases such as cancer and dermatomyositis; however, it remains unclear that Angptl2 functions in acute inflammation. In this study, we investigate whether Angptl2 has a role in acute inflammation in the eye with endotoxin-induced uveitis (EIU). Angptl2 was widely expressed in the normal mouse retina, while Angpt/2 ${ }^{-1-}$ mice did not exhibit any changes in retinal cell marker expression and morphological analyses. Treatment with lipopolysaccharide (LPS) stimulated retinal Angpt/2 mRNA expression in vivo and in vitro. We generated EIU in wild-type (C57BL/6) and Angpt/2 ${ }^{-1-}$ mice by injecting LPS intraperitoneally. Compared with wild-type animals, Angpt/2 ${ }^{-1-}$ mice significantly reduced various ElU-associated cellular and molecular parameters including leukocyte adhesion to the retinal vessels and infiltration into the vitreous cavity and retinal mRNA expression levels of monocyte chemotactic protein-1, intercellular adhesion molecule-1, interleukin (IL)-6, and tumor necrosis factor (TNF)- $\alpha$, together with nuclear translocation of nuclear factor (NF)- $\kappa$ B p65 subunit. In vitro, antibody-based inhibition of $\alpha 5 \beta 1$ integrin, a receptor for Angpt|2, significantly repressed LPS-induced expression of IL- 6 and TNF- $\alpha$, both of which are the major inflammatory cytokines derived from macrophages. The present findings indicate that Angpt/2 mediates endotoxin-induced retinal inflammation through the activation of NF- $\kappa$ B signaling pathway and suggest a potential validity of Angpt/2 as a new molecular target for the treatment of acute inflammation. Laboratory Investigation (2012) 92, 1553-1563; doi:10.1038/labinvest.2012.111; published online 6 August 2012

KEYWORDS: angiopoietin-like protein 2; acute inflammation; endotoxin-induced uveitis; eye; retina

Acute inflammation is the oldest defense mechanism in nature that is initiated by harmful irritation and environments such as infection and tissue injury. ${ }^{1,2}$ Leukocytes in acute inflammation migrate to extravascular tissues to distinguish and eliminate the offending agent, and degrade necrotic tissue components, mostly contributing to tissue repair. In contrast to acute inflammation, leukocytes in chronic inflammation work damage on tissues because of continuous secretion of chemical mediators and toxic oxygen radicals, thereby developing in functional maladaptation and tissue remodeling. ${ }^{1,2}$ However, even in acute inflammation, excessive and repeated acute attacks deteriorate into severe tissue damage and destruction, which is implicated in the pathogenesis of various diseases including vision-threatening uveo-retinal disorders such as Behçet's disease. ${ }^{3}$
Injection of the bacterial endotoxin lipopolysaccharide (LPS) to animals induces acute systemic inflammation that is utilized as an established model for several inflammatory diseases including hepatitis, ${ }^{4}$ arthritis, ${ }^{5}$ and disseminated intravascular coagulation. ${ }^{6}$ LPS-induced ocular inflammations was originally considered as a model of acute inflammation of the uvea and thus termed endotoxin-induced uveitis (EIU). It is characterized by the breakdown of bloodocular barrier represented by protein leakage into the anterior segment, leukocyte adhesion to the retinal vessels, and leukocyte infiltration into the vitreous cavity. ${ }^{7-10}$ These findings have expanded our understanding of the model as a tool to assess acute vascular inflammation not only in the uveal tract but also in the retina. EIU is regarded to represent acute intraocular inflammation as observed in Behçet's disease. ${ }^{7-9}$ LPS application to vascular endothelial cells and

\footnotetext{
'Laboratory of Ocular Cell Biology and Visual Science, Department of Ophthalmology, Hokkaido University Graduate School of Medicine, Sapporo, Japan and 2Department of Molecular Genetics, Graduate School of Medical Sciences, Kumamoto University, Kumamoto, Japan

Correspondence: Dr S Ishida, MD, PhD, Laboratory of Ocular Cell Biology and Visual Science, Department of Ophthalmology, Hokkaido University Graduate School of Medicine, N-15, W-7, Kita-ku, Sapporo 060-8638, Japan.

E-mail: ishidasu@med.hokudai.ac.jp

Received 26 March 2012; revised 31 May 2012; accepted 8 June 2012
} 
macrophages stimulates the activation of nuclear factor (NF) $-\kappa B,{ }^{11-14}$ a transcription factor that controls the expression of a variety of genes related to inflammatory responses, causing the development of diseases. ${ }^{11,14,15}$

Angiopoietin-like protein (Angptl) 2, which has the coiledcoil and fibrinogen-like domains that are conserved in angiopoietins, induces sprouting in human umbilical vein endothelial cells and is required for vascular development in Zebrafish. ${ }^{16,17}$ Recently, Angptl2 is reported to have a critical role in chronic inflammation of adipose tissue via inflammatory signaling in endothelial cells and subsequent recruitment of macrophages. ${ }^{18}$ Transgenic overexpression of Angptl2 in mouse skin caused chronic inflammation characterized by abundant attachment of leukocytes to the vessel walls and increased permeability, whereas Angptl2deficient mice reduced inflammation and ameliorated systemic insulin resistance together with dietary obesity. Most recent studies have shown that Angptl2 also contributes to other chronic inflammatory disorders such as carcinogenesis and metastasis, dermatomyositis, and rheumatoid arthritis. ${ }^{19-22}$ Enhanced expression of Angpt12 has been observed in the sera or lesions of patients with obesity-related metabolic and cardiovascular diseases. ${ }^{18,23-25}$ These recent findings suggest robust evidence that Angptl2 mediates chronic inflammation. It remains unsolved, however, whether there is a relationship between Angptl2 and primitive acute inflammation. In the present study, we investigated the involvement of Angptl2 with endotoxin-induced acute inflammation in mice.

\section{MATERIALS AND METHODS}

\section{Animals and Induction of EIU}

C57BL/6 and Angptl2 knockout ${ }^{18}$ mice at the age of $8-10$ weeks were maintained in the animal facility at Hokkaido University. All animal experiments were conducted in accordance with the ARVO Statement for the Use of Animals in Ophthalmic and Vision Research, and were approved by the Ethics Review Committee for Animal Experimentation of Hokkaido University. Animals received a single intraperitoneal injection of $0.2 \mathrm{mg}$ LPS from Escherichia coli (Sigma-Aldrich, St Louis, MO, USA) in phosphate-buffered saline (PBS). Mice were evaluated at $3 \mathrm{~h}$ (for NF- $\kappa \mathrm{B}$ activation), $6 \mathrm{~h}$ (for various gene expression) and $24 \mathrm{~h}$ (for leukocyte infiltration) after LPS injection, all of which are the established time points for evaluation of pathological parameters in EIU. ${ }^{26-28}$

\section{Cell Culture}

Primary human retinal microvascular endothelial cells (retinal microvasucular endothelial cells (HRMECs); Cell Systems, Kirkland, WA, USA), hTERT-RPE (retinal pigment epithelial cells), Y79 and RAW264.7 cells (American Type Culture Collection, Manassas, VA, USA) were purchased. All cell lines were cultured following the manufacturers' instructions. LPS was added at a final concentration of
$30 \mathrm{ng} / \mathrm{ml}$, and the cells were incubated for $6 \mathrm{~h}$. To inhibit of the bioactivity of $\alpha 5 \beta 1$ integrin, a receptor for Angptl2, RAW264.7 cells were incubated with rat anti- $\alpha 5 \beta 1$ integrin antibody (Millipore, Billerica, MA, USA) or rat nonimmune control antibody (Millipore) for 30 minutes before LPS treatment.

\section{Immunoblot Analysis}

Protein extracts from mouse retinas were solubilized in $2 \times$ SDS (sodium dodecyl sulfate) sample buffer by heating to $100{ }^{\circ} \mathrm{C}$ for $5 \mathrm{~min}$ and separated by $10 \%$ SDS-PAGE (polyacrylamide gel electrophoresis). Proteins were transferred to polyvinylidene fluoride membrane by electroblotting, and immunoblot analyses were performed using goat anti-Angptl2 (R\&D systems, Minneapolis, MN, USA) and rabbit anti- $\beta$ actin antibodies (Cell Signaling Technology, Danvers, MA, USA) as previously described. ${ }^{29}$

\section{Immunofluorescence Microscopy}

Serial paraffin sections of mouse retinas were deparaffinized and hydrated through exposure with xylene and graded alcohols followed by water. As a pretreatment, microwavebased antigen retrieval was performed in $1 \mathrm{mM}$ EDTA buffer $(\mathrm{pH}$ 8). Sections were probed with the following primary antibodies: goat anti-Angpt12, rabbit anti-NF- $\kappa$ B p65 (Cell Signaling Technology), and mouse anti-glutamine synthetase (Millipore) antibodies. The secondary antibodies for fluorescent detection were AlexaFluor 488 and 546 (Life Technologies, Carlsbad, CA, USA). Sections were visualized under a FluoView FV10i-DOC (Olympus, Tokyo, Japan).

\section{Quantification of Retinal Adherent Leukocytes}

The retinal vasculature and adherent leukocytes were imaged by perfusion-labeling with fluorescein isothiocyanate (FITC)coupled concanavalin A lectin (Con A; Vector, Burlingame, CA, USA), as described previously. ${ }^{26-28}$ Briefly, the chest cavity was opened and a cannula was introduced into the left ventricle under deep anesthesia. After injection of PBS to remove erythrocytes and nonadherent leukocytes, FITCconjugated Con A was perfused. After the eyes were enucleated, the retinas were flatmounted. The flatmounts were visualized under a Keyence BZ-9000 (Tokyo, Japan), and the total number of Con A-stained adherent leukocytes per retina was counted in a masked fashion.

\section{Quantification of Vitreous Infiltrating Leukocytes}

The number of leukocytes infiltrating into the vitreous cavity was analyzed as described previously. ${ }^{27}$ Briefly, tissues were fixed and embedded in paraffin using standard techniques. Three $5-\mu \mathrm{m}$ sections were prepared at a distance of $100 \mu \mathrm{m}$ to each other with the middle section passing through the optic nerve. All sections were stained with hematoxylin and eosin, and the number of cells in the vitreous cavity was counted in a masked fashion. 


\section{Real-Time Quantitative and Reverse Transcription PCR Analyses}

Total RNA was isolated from tissues and cells using TRIzol (Life Technologies). Reverse transcription was performed with GoScrip Reverse Transcriptase (Promega, Madison, WI, USA) and oligo dT(20) primers, essentially as described. ${ }^{30}$ Real-time quantitative PCR was performed using the GoTaq qPCR Master Mix (Promega), THUNDERBIRD Probe qPCR Mix (TOYOBO, Tokyo, Japan) and StepOne plus System (Life Technologies). All primers are listed in Table 1. Taqman gene expression assay for human HPRT1 (Life Technologies) was performed. The correct amplification of a specific product was confirmed by the dissociation temperature of the product and agarose gel electrophoresis. All experimental samples were normalized using human HPRT1 or mouse Gapdh as an internal control.

Table 1 Primer sequences used in quantitative RT-PCR

\begin{tabular}{|c|c|}
\hline Target gene & Sequence \\
\hline \multirow[t]{2}{*}{ Human ANGPTL2 } & Forward 5'-CCCCAACACCTTCCACTAAG-3' \\
\hline & Reverse 5'-AACAGAATCCAGCATCCCG-3' \\
\hline \multirow[t]{2}{*}{ Mouse Angpt/2 } & Forward 5'-GGAGGTTGGACTGTCATCCAGAG-3 \\
\hline & Reverse 5'-GCCTTGGTTCGTCAGCCAGTA-3' \\
\hline \multirow[t]{2}{*}{ Rho } & Forward 5'-ATGGGTGTGGTCTTCACCTG-3' \\
\hline & Reverse $5^{\prime}$-GAACATTGCATGCCCTCAG-3' \\
\hline \multirow[t]{2}{*}{ Opn1mw } & Forward 5'-ATCGTGCTCTGCTACCTCCA-3' \\
\hline & Reverse $5^{\prime}-\pi T C T G T G G T T G C C A C T G-3^{\prime}$ \\
\hline \multirow[t]{2}{*}{ Grm6 } & Forward 5'-TGTGCCAGAGACCTTCAATG-3' \\
\hline & Reverse 5'-AGTGTGGTCGTITGGATGTAG-3' \\
\hline \multirow[t]{2}{*}{ Thy 1} & Forward 5'-GAGTCCAGAATCCAAGTCGG-3' \\
\hline & Reverse 5'-AGTCCAGGCGAAGGTITG-3' \\
\hline \multirow[t]{2}{*}{$C C L 2 / M C P-1$} & Forward 5'-TTGGCTCAGCCAGATGCA-3' \\
\hline & Reverse 5'-CCTACTCATTGGGATCATCTTGC-3' \\
\hline \multirow[t]{2}{*}{ ICAM-1 } & Forward 5'-CCTGTTTCCTGGCTCTGAAG-3' \\
\hline & Reverse 5'-GTCTGCTGAGACCCCTCTTG-3' \\
\hline \multirow[t]{2}{*}{ IL-6 } & Forward 5'-CACAGAGGATACCACTCCCAACA-3 \\
\hline & Reverse 5'-TCCACGATTCCCAGAGAAACA-3' \\
\hline \multirow[t]{2}{*}{$T N F-\alpha$} & Forward 5'-GGTGCCTATGTCTCAGCCTCTT-3' \\
\hline & Reverse 5'-CGATCACCCCGAAGTTCAGTA-3' \\
\hline \multirow[t]{2}{*}{ Itga5 } & Forward 5'-CTTCTCCGTGGAGTITACCG-3' \\
\hline & Reverse 5'-GCTGTCAAATTGAATGGTGGTG-3' \\
\hline \multirow[t]{2}{*}{$\mid \operatorname{tg} b 1$} & Forward 5'-GCAACGCATATCTGGAAACTTG-3' \\
\hline & Reverse 5'-CAAAGTGAAACCCAGCATCC-3' \\
\hline \multirow[t]{2}{*}{ Gapdh } & Forward 5'-AGGTCGGTGTGAACGGATTTG-3' \\
\hline & Reverse $5^{\prime}$-TGTAGACCATGTAGTTGAGGTCA-3' \\
\hline
\end{tabular}

Abbreviations: ANGPTL2, angiopoietin-like protein; CCL2, C-C chemokine ligand; ICAM, intercellular adhesion molecule; $I L$, interleukin; Rho, rhodopsin; RT-PCR, reverse transcription PCR; TNF- $\alpha$, tumor necrosis factor- $\alpha$.

\section{Enzyme Linked Immunosorbent Assay (ELISA) for NF- $\kappa$ B p65 Subunit}

Nuclear extracts were purified from mouse retinas with Nuclear Extraction Kit (Active Motif, Carlsbad, CA, USA). Activation of NF- $\kappa \mathrm{B}$ was determined by measuring the NF- $\kappa \mathrm{B}$ subunit p65 protein level in the nuclear extracts with an NF- $\kappa$ B detection kit (Cayman Chemical, Ann Arbor, MI, USA) according to the manufacturer's instruction. The tissue sample concentration was calculated from a standard curve and corrected for protein concentration.

\section{Statistical Analysis}

All results ware expressed as mean \pm s.e.m. (standard error for mean). The values were processed for statistical analysis (Student's $t$-test). Differences between the means were considered statistically significant when the $P$ values were $<0.05$.

\section{RESULTS}

\section{Angptl2 Expression in Retinas of Wild-Type but Not} Angpt/2 ${ }^{-1-}$ Mice

Angptl2 mRNA has recently proven to be expressed in the heart, lung, kidney, skeletal muscle, and adipose tissue ${ }^{18}$; however, retinal expression remains to be clarified. Immunoblot analysis revealed a predicted protein band of approximately $57 \mathrm{kDa}$ in wild-type mouse retina (Figure 1a), and Angptl2 immunoreactivity were widely distributed in the retina (Figures $1 \mathrm{~b}$ and $\mathrm{c}$ ), whereas both immunoblot and immunofluorescence signals were abolished in Angptl2 ${ }^{-1-}$ mice (Figures 1a, d and e). We performed histological and real-time quantitative PCR analyses to check whether Angptl2 deficiency affects retinal development. Angptl2 ${ }^{-/-}$mice exhibited no obvious morphological phenotype in the retina at 8 weeks of age (Figures $1 \mathrm{f}$ and g). No significant difference was detected in gene expression of various retinal cell markers including Rho (rhodopsin), Opn $1 \mathrm{mw}$ (opsin 1 (cone pigments), medium-wave-sensitive), Grm6 (glutamate receptor, metabotropic 6) and Thy1 (thymus cell antigen 1) between wild-type and Angptl2 ${ }^{-1-}$ mice (Rho, fold change $=$ 1.01; Opn1mw, fold change $=1.06 ;$ Grm6, fold change $=1.11$; Thy1, fold change $=1.07 ; P>0.05$ for all) (Figure $1 \mathrm{~h}$ ).

\section{LPS-Stimulated Induction of Angpt/2 mRNA Expression}

To define the association of Angptl2 with acute inflammation, we examined Angptl2 gene expression following the in vivo and in vitro stimulation with LPS by real-time quantitative PCR. Angptl2 mRNA level was significantly increased in the retina of EIU mice compared with that of normal controls (fold change $=3.42, P<0.01$ ) (Figure 2a). In vitro, LPS administration led to significant upregulation of ANGPTL2 (Angptl2 for mice) gene expression in various cell lines including HRMEC, hTERT-RPE, Y79 (retinoblastoma cells) and RAW264.7 (macrophages) (HRMEC, fold change $=3.01, P<0.01 ;$ hTERT-RPE, fold change $=1.85$, $P<0.05$; Y79, fold change $=1.29, P<0.05 ;$ RAW264.7, fold change $=3.42, P<0.01)$ (Figures $2 \mathrm{~b}-\mathrm{e}$ ). 
a
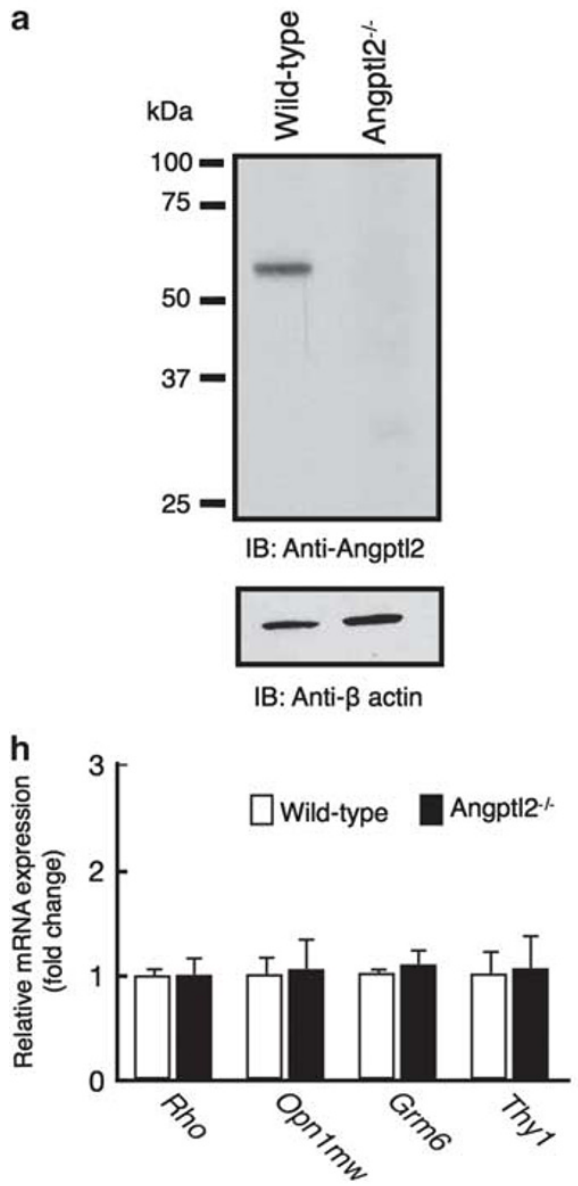

Wild-type
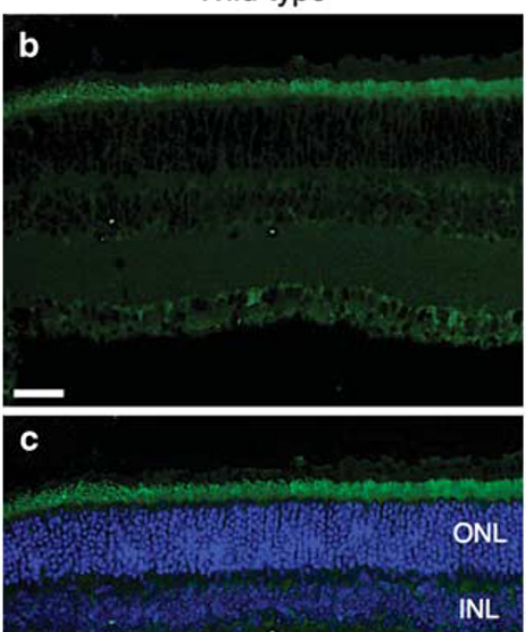

INL

GCL
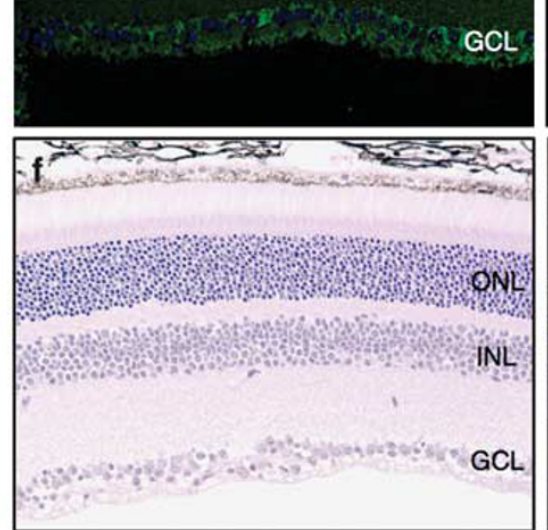

Angptl2\%
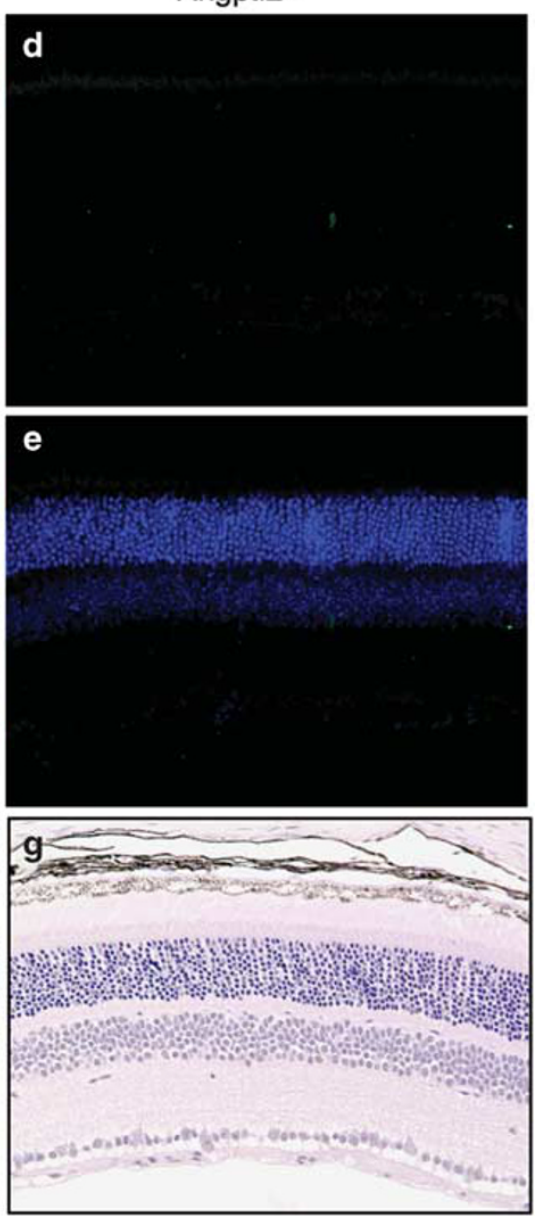

Figure 1 Angiopoietin-like protein (Angptl)2 Expression in Retinas of Wild-Type but Not Angpt/2-/- Mice. (a) Immunoblotting for Angpt/2 protein. Protein extracts were prepared from retinas of wild-type and Angpt $/ 2^{-1-}$ mice. (b-e) Localization of Angptl2 protein in mouse retinas. Angptl2 (green) and DAPI (blue). Scale bar, $30 \mu \mathrm{m}$. (f, g) Hematoxylin and eosin staining of wild-type and Angpt/2-/- mice retina at 8 weeks of age. (h) Relative mRNA expression in wild-type and Angpt/2-/- mice retinas. Fold changes in expression of target genes (Rho, (rhodopsin) Opn $1 \mathrm{mw}$, Grm6 and Thy 1 ) relative to the internal control. Wild-type gene expression was used as a reference ( $n=7$ per group). White and black bars indicate wild-type and Angpt/2 ${ }^{-1-}$ mice, respectively. $\mathrm{GCL}$, ganglion cell layer; INL, inner nuclear layer; $\mathrm{ONL}$, outer nuclear layer.

\section{Reduction of Retinal Leukocyte Adhesion in Angpt/2 ${ }^{-/-}$ Mice with EIU}

To examine whether Angptl2 deficiency alters acute retinal inflammation, we evaluated the number of leukocytes adhering to the retinal vessels in wild-type, Angptl2 ${ }^{+/-}$and Angptl2 ${ }^{-/-}$ mice with EIU. Compared with wild-type animals with EIU $\left(232 \pm 26\right.$ cells/retina; Figures 3a, b, and g), EIU Angptl2 ${ }^{-/-}$ mice showed a significant $(P<0.01)$ decrease in retinal leukocyte adhesion to $49.1 \%(114 \pm 24$ cells/retina; Figures $3 \mathrm{e}$, f, and $\mathrm{g}$ ), whereas no significant difference was detected between wild-type and Angptl2 ${ }^{+/-}$mice with EIU ( $232 \pm 26$ vs $200 \pm 16$ cells/retina, $P>0.05$; Figures $3 c$, d, and g).

\section{Reduction of Vitreous Leukocyte Infiltration in Angpt/2 ${ }^{-1-}$ Mice with EIU}

To further confirm the inhibitory effect of Angptl2 deficiency on acute retinal inflammation (Figure 3), we quantified the number of leukocytes infiltrating into the vitreous cavity adjacent to the optic disc in wild-type, Angptl2 ${ }^{+/-}$and Angptl2 ${ }^{-/-}$mice with EIU. Leukocyte infiltration into the vitreous, which markedly increased with induction of EIU, significantly decreased in Angptl2 ${ }^{-/-}$mice to $22.9 \%$ (wild-type, $35 \pm 8$ cells/section; Angptl2 ${ }^{+/-}, 25 \pm 9$ cells/ section, $P>0.05 ;$ Angptl2 ${ }^{-/-}, 8 \pm 3$ cells/section, $P<0.01$ ) (Figures $4 \mathrm{a}-\mathrm{d}$ ).

\section{Reduction of Retinal Inflammatory Molecules in Angpt/2 ${ }^{-1-}$ Mice with or without EIU}

To determine molecular mechanisms in which Angptl2 deficiency led to suppression of cellular inflammatory responses in EIU (Figures 3 and 4), retinal mRNA expression levels of $\mathrm{C}-\mathrm{C}$ chemokine ligand $(C C L)$ 2/monocyte chemotactic protein $(M C P)-1$, intercellular adhesion molecule (ICAM)-1, interleukin (IL)-6 and tumor necrosis factor $(T N F)-\alpha$ were 

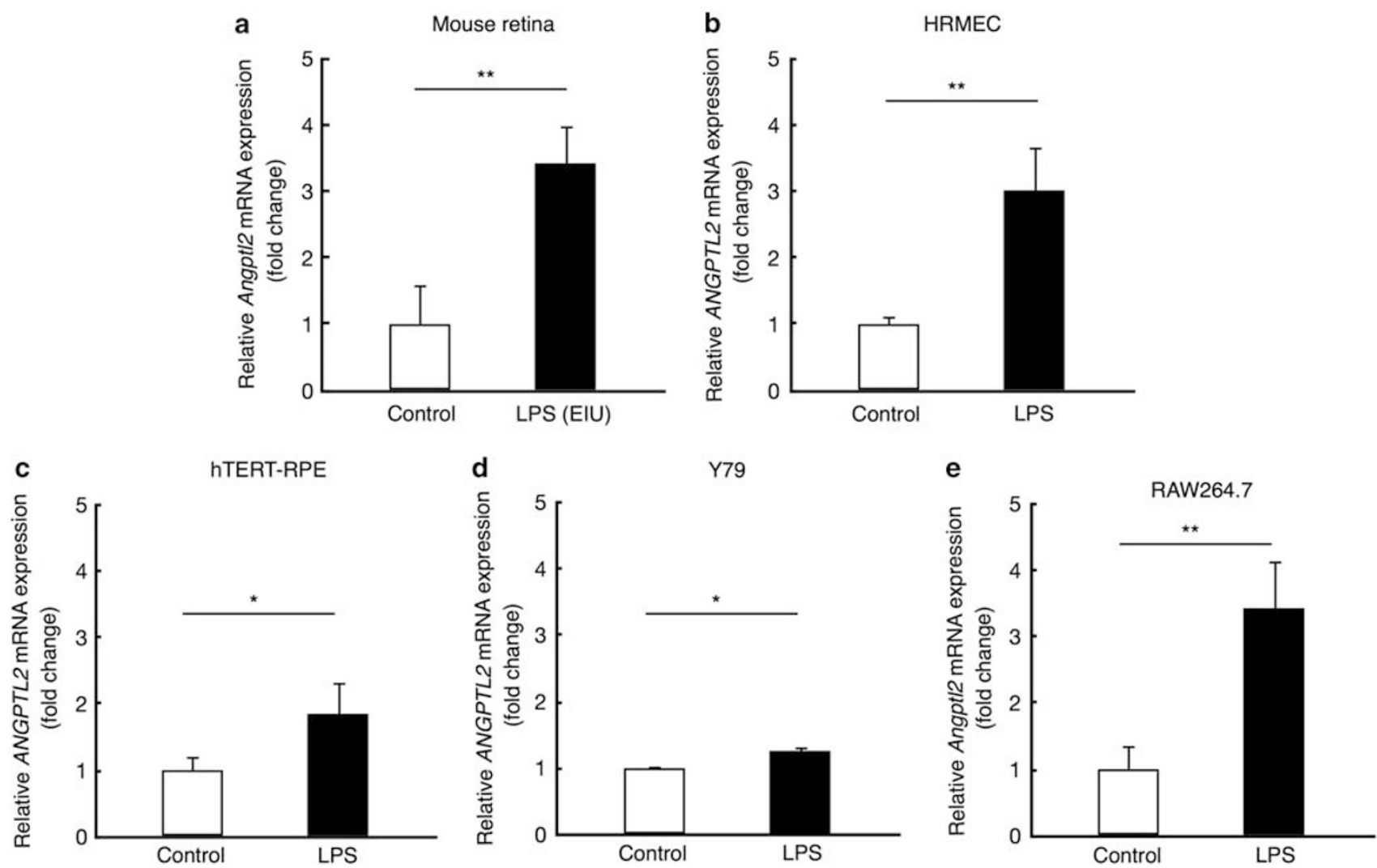

Figure 2 lipopolysaccharide (LPS)-Stimulated Induction of Angpt/2 mRNA Expression. (a) Angiopoietin-like protein (Angptl)2 mRNA expression in wild-type mice retina with endotoxin-induced uveitis (EIU). Angpt/2 mRNA expression of LPS-treated retinal microvasucular endothelial cells (HRMEC) (b), hTERT-RPE (retinal pigment epithelial cells) (c), Y79 (d) and RAW264.7 cells (e). Real-time quantitative PCR for Angpt/2 after stimulation with LPS. ${ }^{*} P<0.05,{ }^{* *} P<0.01$ ( $n=6$ per group).

measured by real-time quantitative PCR. Compared with wild-type normal controls, Angptl2 deficiency decreased the endogenous baseline expression of all these inflammationrelated molecules (CCL2/MCP-1, fold change $=0.406$, $P<0.01 ;$ ICAM-1, fold change $=0.445, P<0.05 ; I L-6$, fold change $=0.170, \quad P<0.01 ; \quad T N F-\alpha$ fold change $=0.473$, $P<0.05$ ) (Figure 5a). Subsequently, we measured the gene expression levels in EIU. EIU induction to wild-type mice dramatically upregulated all of the four genes compared with normal controls (CCL2/MCP-1, fold change $=1136.8$, $P<0.01$; ICAM- 1 , fold change $=54.15, P<0.05 ; I L-6$, fold change $=3.10, P<0.01 ; T N F-\alpha$ fold change $=1.53, P<0.05$ ), as reported previously. ${ }^{26-28}$ Compared with wild-type EIU, Angptl2 deficiency also declined the EIU-associated upregulated expression of all these inflammatory molecules $(C C L 2 / M C P-1$, fold change $=0.318, P<0.01 ; I C A M-1$, fold change $=0.246, P<0.01 ; I L-6$, fold change $=0.545, P<0.05$; $T N F-\alpha$ fold change $=0.659, P<0.05)($ Figure $5 b)$.

\section{Reduction of NF- $\kappa$ B Activation in Angpt/2 ${ }^{-/-}$Mice with EIU}

To determine the upstream intracellular signaling pathway of the reduced cellular (Figures 3 and 4) and molecular
(Figure 5) inflammatory responses in Angptl2 ${ }^{-/-}$EIU, we examined the nuclear translocation of NF- $\kappa \mathrm{B}$ p 65 by immunofluorescence. EIU induction to wild-type mice substantially increased the number of NF- $\kappa \mathrm{B}$ p65-positive cells colocalized with immunoreactivity of glutamine synthetase, suggesting the activation of NF- $\kappa \mathrm{B}$ p 65 in glutamine synthetase-positive Müller glial cells (Figures 6a and b). Compared with wild-type EIU, Angptl2 deficiency led to significant $(P<0.05)$ suppression of the EIUassociated nuclear translocation of NF- $\kappa \mathrm{B}$ p65 by $38.9 \%$ (Figures 6c-e).

To confirm the morphometric data (Figures 6c-e), we quantitatively measured nuclear protein levels of NF- $\kappa \mathrm{B}$ p65 by ELISA following nuclear extraction from the whole retina. Compared with wild-type EIU, Angptl2 deficiency led to significant $(P<0.05)$ reduction of the EIU-associated nuclear NF- $\kappa$ B p 65 protein levels by $17.5 \%$ (Figure 6f).

\section{Reduction of LPS-Stimulated Cytokine Expression by Inhibiting $\alpha 5 \beta 1$ Integrin}

Angptl2 interacts with $\alpha 5 \beta 1$ integrin that activates its downstream NF- $\kappa$ B pathway in vascular endothelial cells and 
macrophages. ${ }^{18,22}$ To investigate whether LPS-stimulated Angptl2 induces inflammatory responses via $\alpha 5 \beta 1$ integrin, we performed in vitro experiments with a neutralizing antibody. First, we confirmed using reverse transcription PCR analyses the constitutive expression of Itga5 (integrin $\alpha 5$ subunit) and Igtb1 (integrin $\beta 1$ subunit) in RAW264.7 macrophages (Figure 7a), which proved to be the rich source of Angptl2 (Figure 2e). LPS administration to macrophages significantly upregulated the two major inflammatory cytokines $(T N F-\alpha$, fold change $=34.7, P<0.01 ; I L-6$, fold change $=7947.4, P<0.01$ ), both of which were significantly suppressed by anti- $\alpha 5 \beta 1$ antibody $(T N F-\alpha$, fold change $=22.0, P<0.01$; IL-6, fold change $=4728.8, P<0.05$ ), but not by control antibody $(T N F-\alpha$, fold change $=33.7$, $P>0.05 ; I L-6$, fold change $=7836.6, P>0.05) \quad($ Figures $7 \mathrm{~b}$ and c). LPS application to RAW264.7 cells did not alter Itga5 or Igtb1 gene expression (data not shown), suggesting a ligand-based regulation in the Angpt12/ $\alpha 5 \beta 1$-mediated proinflammatory system.

\section{DISCUSSION}

The present study provided, for the first time to our knowledge, several important data concerning the biological effects of Angptl2 on acute retinal inflammation. First, Angptl2 was shown to be ubiquitously expressed in the retina (Figure 1). Second, LPS stimulation in vitro and in vivo significantly induced Angptl2 mRNA expression (Figure 2). Importantly, Angptl2 deficiency in EIU attenuated several cellular and molecular inflammatory parameters including leukocyte adhesion (Figure 3) and infiltration (Figure 4), the upregulated expression of various inflammatory mediators (Figure 5), and NF- $\kappa \mathrm{B}$ activation (Figure 6). Moreover, LPS-induced expression of inflammatory cytokines in vitro was significantly suppressed by inhibiting $\alpha 5 \beta 1$ integrin, a receptor for Angptl2 (Figure 7).

The present study is the first to show the constitutive expression of Angptl2 in the retina, whereas Angptl2 mRNA has so far been detected mainly in the heart, lung, kidney, skeletal muscle, and adipose tissue, ${ }^{18}$ most of which are the
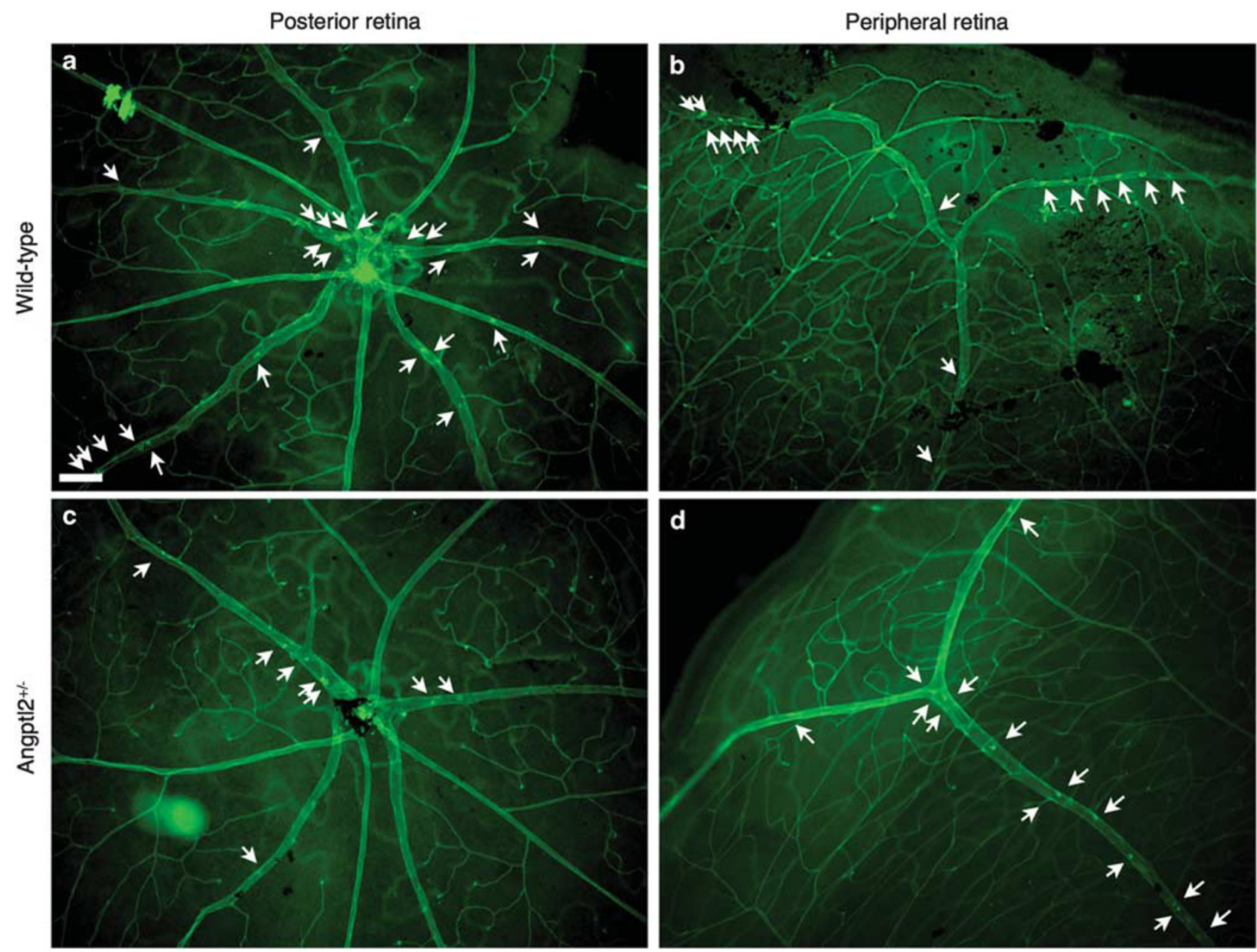

Figure 3 Reduction of Retinal Leukocyte Adhesion in Angiopoietin-like protein (Angptl)2 $2^{-1-}$ Mice with endotoxin-induced uveitis (ElU). Flatmounted retinas from wild-type $(\mathbf{a}, \mathbf{b})$, Angpt $/ 2^{+/-}(\mathbf{c}, \mathbf{d})$ and Angpt $/ 2^{-/-}$mice $(\mathbf{e}, \mathbf{f})$ with ElU. Arrows indicate firmly adhering leukocytes to the inflamed retinal vasculature. Scale bar, $100 \mu \mathrm{m}$. (g) Quantification of the number of retinal adherent leukocytes. ${ }^{* *} P<0.01$ ( $n=10$ to 11 per group). White, gray and black bars indicate wild-type, Angpt/2 $2^{+/}$and Angpt $/ 2^{-/-}$mice, respectively. 

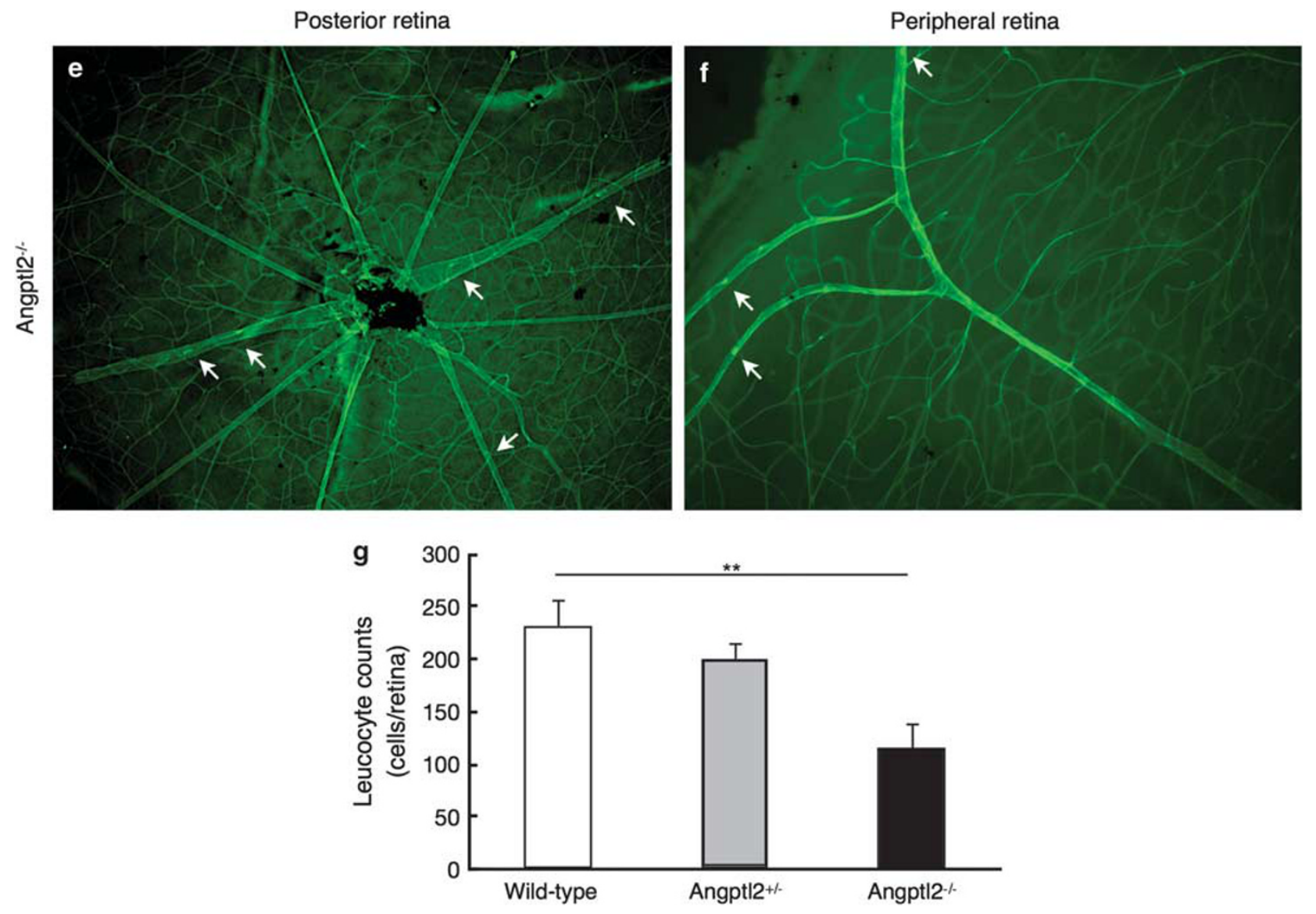

Figure 3 Continued.

target organs for lifestyle-related metabolic disorders. Importantly, Angptl2 $2^{-1-}$ mice did not show any remarkable changes in retinal morphology and gene expression of various retinal cell markers (Figure 1). These results suggest that Angptl2 is not required for normal retinal development although its broad distribution in the whole retinal layer suggests some possible role in adults.

Recently, Angptl2 mRNA expression has proven to be enhanced by hypoxia and palmitate-induced endoplasmic reticulum (ER) stress in adipocytes, indicating its possible role in obesity-related chronic inflammation. ${ }^{18}$ Our data first revealed that Angptl2 mRNA expression was stimulated by the bacterial endotoxin LPS (Figure 2), a known inducer of primitive acute inflammation. We confirmed that the endotoxin-induced Angptl2 mRNA expression was observed in the retina, as well as in multiple retinal cell lines and macrophages related to the pathogenesis of EIU (Figure 2). Palmitate application to pancreatic $\beta$-cells has been reported to activate the ER stress-induced transcription factor $\mathrm{CHOP}$ (C/EBP homologous protein). ${ }^{31}$ Interestingly, LPS stimulation to macrophages also induced the ER stressCHOP pathway. ${ }^{32}$ However, our in vitro experiments with small interfering RNA-based knockdown of $C H O P$ revealed that this transcription factor did not mediate LPS-stimulated expression of Angptl2 in macrophages (data not shown), suggesting different induction pathways for Angptl2 between bacterial endotoxin and saturated fatty acid, which cause acute and chronic inflammation, respectively.

EIU is a useful model for assessing acute vascular inflammation involving the major components in the innate immune system. ${ }^{7-10}$ Angptl2 ${ }^{-/-}$mice with EIU exhibited significant reduction of accumulation of adherent leukocytes to the retinal vessels (Figure 3) and infiltrating leukocytes into the vitreous cavity (Figure 4). These findings provide the first evidence that Angptl2 has a significant role in acute inflammation. In addition to the investigation into cellular reactions, comparable experiments clarified significant suppression of CCL2/MCP-1 and ICAM-1 mRNA levels in Angptl2 ${ }^{-1-}$ mice (Figure 5), both of which have pivotal roles in leukocyte recruitment and adhesion during vascular inflammation. ${ }^{33,34}$ The interaction between ICAM-1 and its counter receptor $\beta 2$ (CD18)-integrins (ie, LFA (leukocyte function-associated antigen)-1 and Mac-1) has been shown to have an essential role in the leukocyte-endothelial interaction in the pathogenesis of EIU. ${ }^{34,35}$ ICAM-1 expression is upregulated in the retina following LPS 

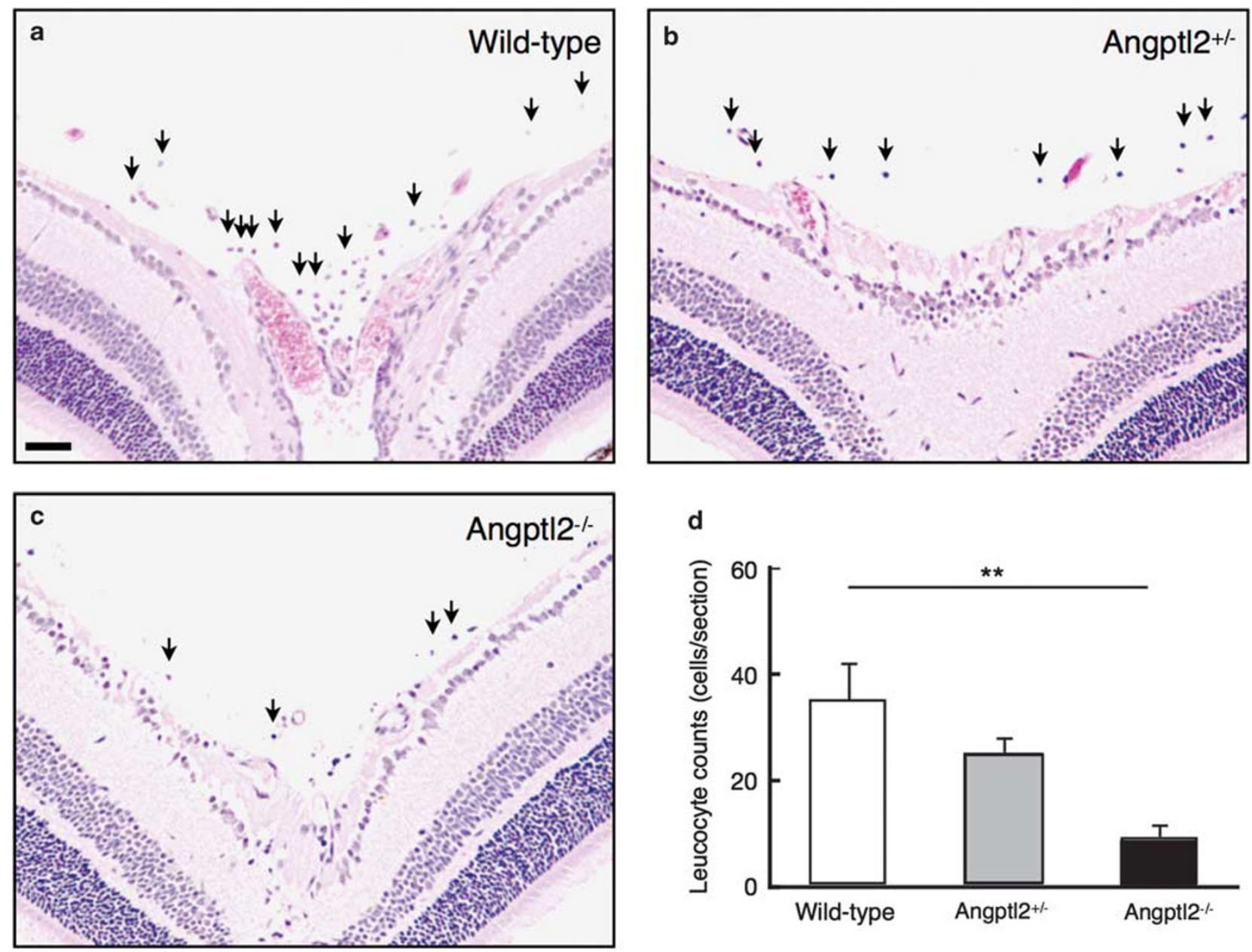

Figure 4 Reduction of Vitreous Leukocyte Infiltration in Angiopoietin-like protein (Angpt/)2 ${ }^{-/}$Mice with Endotoxin-Induced Uveitis (EIU).

Representative micrographs of leukocyte infiltration into the vitreous of wild-type (a), Angpt/2 ${ }^{+/-}$(b) and Angpt $/ 2^{-/-}$mice (c) with EIU. Arrows indicate the infiltrating leukocytes. Scale bar, $30 \mu \mathrm{m}$. (d) Quantification of the number of leukocytes in the vitreous cavity. ${ }^{* *} P<0.01$ ( $n=8$ per group). White, gray and black bars indicate wild-type, Angpt/2 ${ }^{+/-}$and Angpt/2-1- mice, respectively.

a

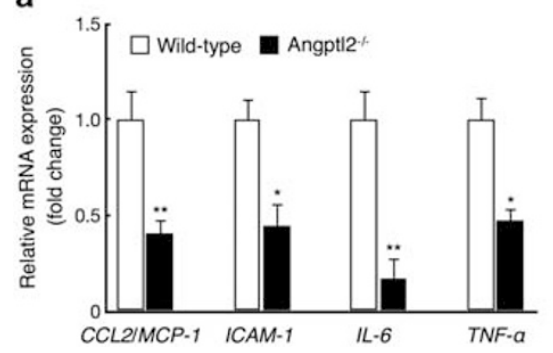

b

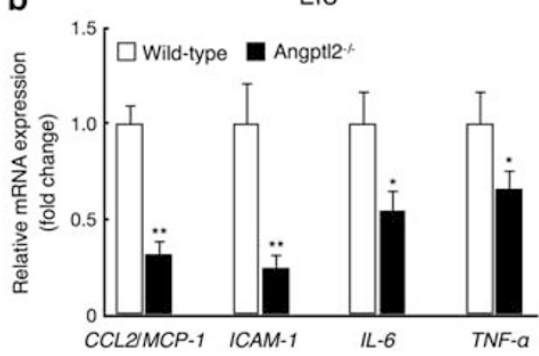

Figure 5 Reduction of Retinal Inflammatory Molecules in Angiopoietin-like Protein (Angpt/)2 ${ }^{-1-}$ Mice with or without Endotoxin-Induced Uveitis (EIU). (a) Gene expression levels of CCL2 (C-C chemokine ligand)/MCP-1 (monocyte chemotactic protein), ICAM-1 (intercellular adhesion molecule), IL-6 (interleukin) and tumor necrosis factor (TNF)- $\alpha$ in retinas from wild-type and Angpt/2 ${ }^{-1-}$ mice. (b) Gene expression levels of CCL2/MCP-1, ICAM-1, IL-6 and TNF- $\alpha$ in retinas from wild-type and Angpt/2 ${ }^{-1-}$ mice with EIU. ${ }^{*} P<0.05,{ }^{*} P<0.01$ ( $n=7$ to 9 per group). Wild-type gene expression was used as a reference. White and black bars indicate wild-type and Angpt $/ 2^{-/-}$mice, respectively.

application, and antibody-based blockade of ICAM-1 leads to significant suppression of EIU development. ${ }^{34}$ CCL2/MCP-1, the major chemotactic activator of monocytes and neutrophils, is required for leukocyte recruitment to the sites of inflammation in EIU, ${ }^{36}$ as genetic ablation of CCL2/ MCP-1 leads to a substantial decrease in ocular inflammation 


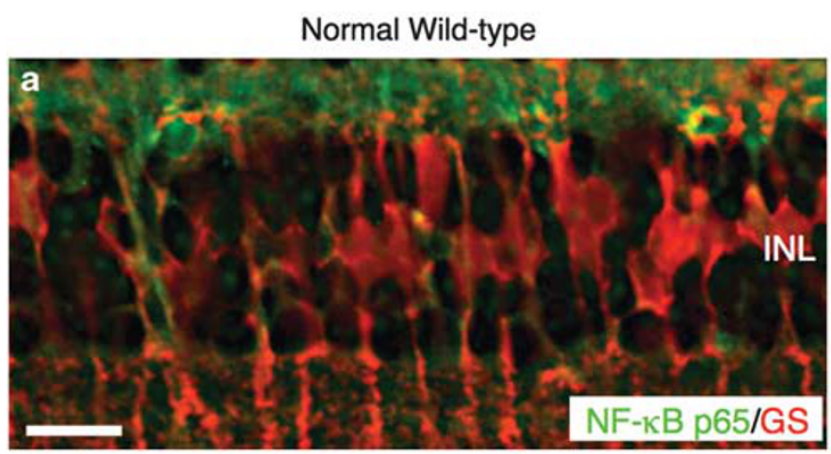

EIU Wild-type
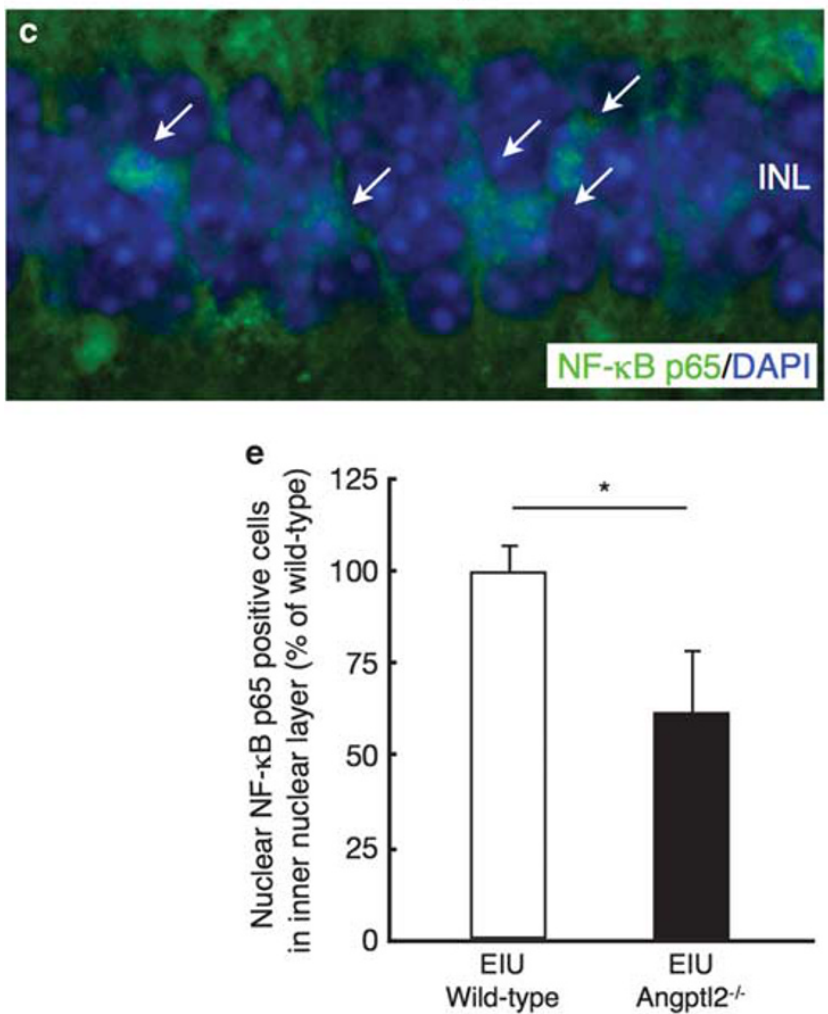

EIU Wild-type

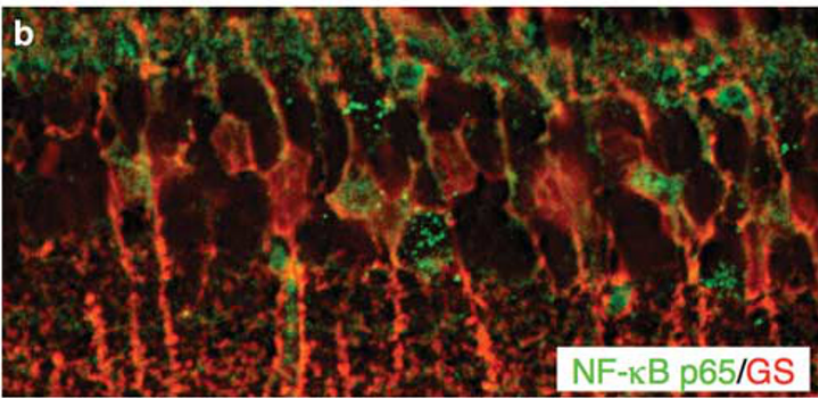

EIU Angpt12\%
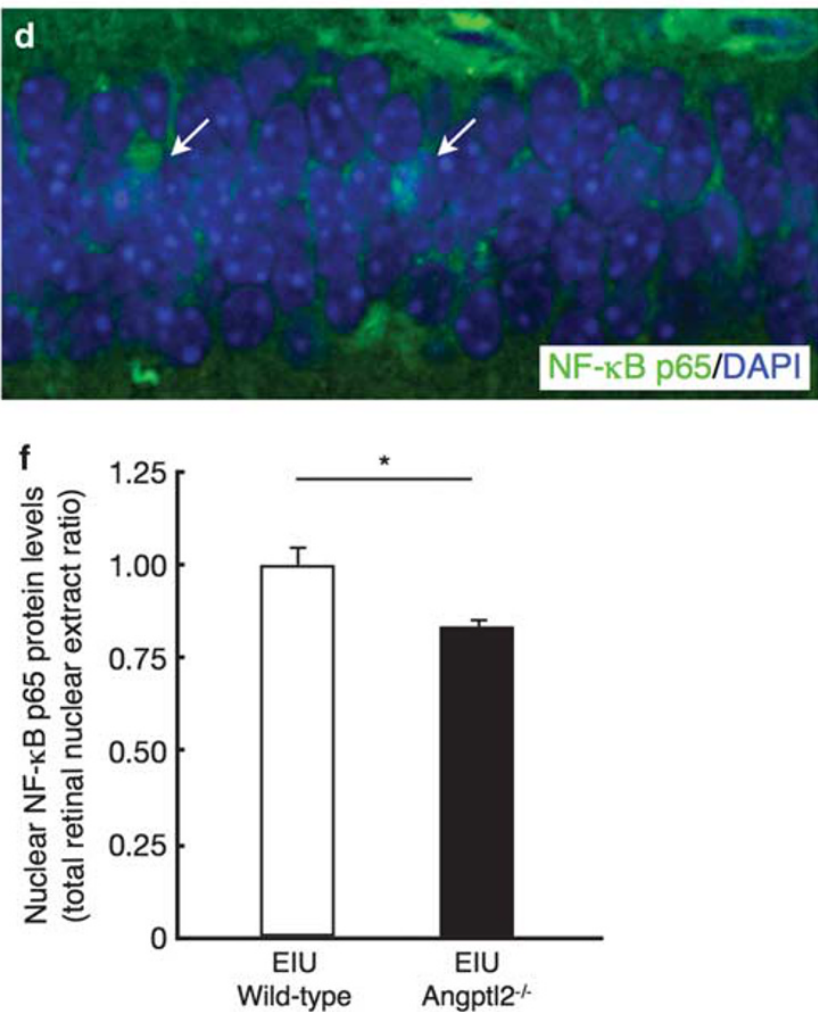

Figure 6 Reduction of NF- $\kappa$ B Activation in Angiopoietin-like protein (Angpt/2) ${ }^{-/-}$Mice with endotoxin-induced uveitis (EIU). Immunofluorescence for NF- $\kappa$ B p65 (green) and glutamine synthetase (GS) (red) in the retinal sections from wild-type mice without (a) and with (b) EIU. Localization of NF- $\kappa$ B p65 in retinas from wild-type (c) and Angpt/2 $2^{-1-}$ (d) mice with EIU. NF- $\kappa$ B p65 (green) and DAPI (blue). Scale bar, $10 \mu$ m. Arrows indicate merged images of NF- $\kappa$ B p65 and DAPI staining. (e) The number of nuclear NF- $\kappa$ B p65-positive cells in the inner nuclear layer. (f) Nuclear NF- $\kappa$ B p65 protein levels detected by ELISA after nuclear extraction from the whole retina. ${ }^{*} P<0.05,{ }^{* *} P<0.01$ ( $n=9$ to 13 per group). White and black bars indicate wild-type and Angpt/2-/- mice with EIU, respectively. INL, inner nuclear layer.

in mice with EIU. ${ }^{37}$ Moreover, we unraveled the inhibitory effects of Angplt2 deficiency on gene expression levels of the two major proinflammatory cytokines $I L-6$ and $T N F-\alpha$ (Figure 5), both of which facilitate ocular inflammation in EIU, ${ }^{9,38}$ in concert with the leukocyte chemotactic and adhesion factors CCL2/MCP-1 and ICAM-1. Consequently, Angptl2 deficiency-mediated attenuation of these inflammatory chemical mediators (Figure 5) is thought to result in decreased vascular inflammation in EIU (Figures 3 and 4).
The present study revealed that Angptl2 deficiency led to significant suppression of EIU-associated nuclear translocation of NF- $\kappa \mathrm{B}$ (Figure 6). NF- $\kappa \mathrm{B}$, the p65/p50 heterodimer, is a transcription factor that regulates numerous gene expression coordinating inflammatory responses. Activation of NF- $\kappa \mathrm{B}$ signaling contributes to the development of various inflammatory disorders such as EIU, ${ }^{11-15,39}$ activating gene expression including CCL2/MCP-1, ICAM-1, IL-6 and $T N F-\alpha,{ }^{14,15,40,41}$ all of which were suggested to enhance acute 
a

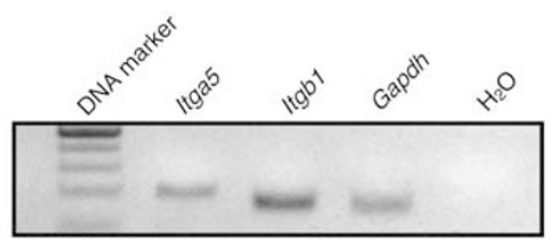

b
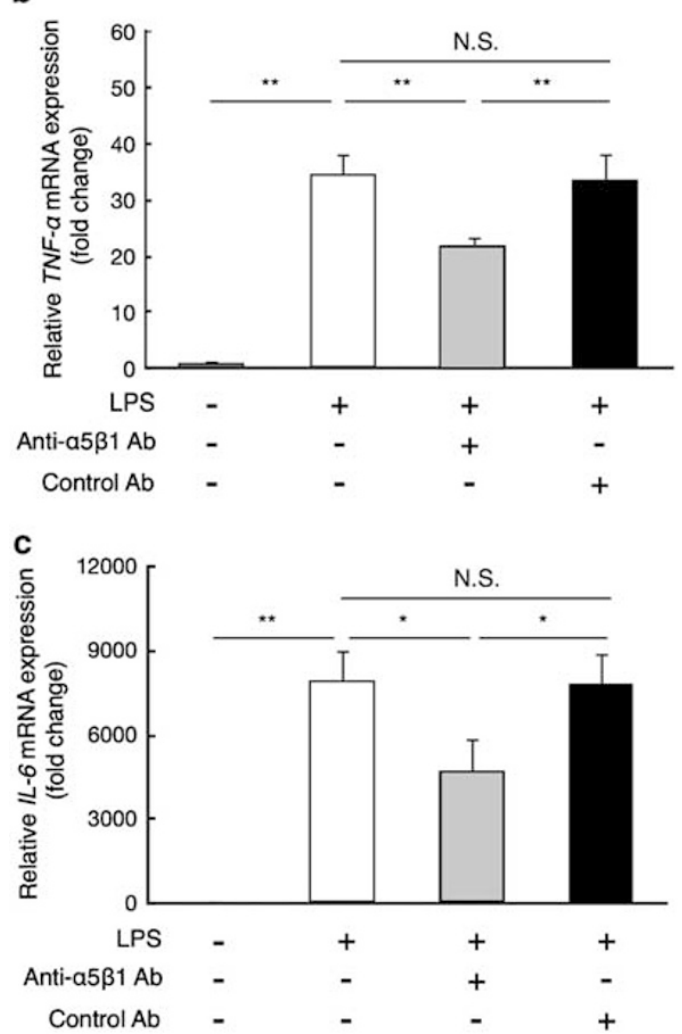

Figure 7 Reduction of lipopolysaccharide (LPS)-Stimulated Cytokine Expression by Inhibiting $\alpha 5 \beta 1$ Integrin. (a) Gene expression analysis of Itga5 and Itgb1 in RAW264.7 cells. Real-time quantitative PCR for tumor necrosis factor (TNF)- $\alpha$ (b) and (interleukin) IL-6 (c) in RAW264.7 cells. RAW264.7 cells were pre-incubated with anti- $\alpha 5 \beta 1$ integrin or control antibody before stimulation with LPS. ${ }^{*} P<0.05,{ }^{* *} P<0.01(n=8$ per group).

inflammation in the downstream of Angptl2 (Figure 5). Angptl2 has recently been shown to interact with cell-surface $\alpha 5 \beta 1$ integrin that mediates its downstream NF- $\kappa \mathrm{B}$ activation in vascular endothelial cells and macrophages. ${ }^{18,22}$ Furthermore, administration of recombinant Angptl2 protein to keratinocytes enhanced the expression of IL- $1 \beta$ and IL- 6 via the NF- $\kappa$ B cascade. ${ }^{22}$ These recent findings are compatible with our present data suggesting that LPSinduced retinal expression of Angptl2 (Figures 1 and 2) causes NF- $\kappa \mathrm{B}$ activation (Figure 6) and subsequent molecular (Figure 5) and cellular (Figures 3 and 4) reactions. Moreover, LPS-induced expression of TNF- $\alpha$ and $I L-6$ in Angptl2-bearing macrophages (Figure 2e) was mediated by $\alpha 5 \beta 1$ integrin (Figure 7). The in vitro data further confirmed the Angptl2/ $\alpha 5 \beta 1$-mediated proinflammatory signaling in macrophages, the major leukocytes infiltrating into the eye with EIU. Accordingly, these infiltrating cells, as well as the inflamed retina, would also be the source of Angptl2 (Figure 2a), phosphorylated NF- $\kappa$ B (Figure 6f) and inflammatory cytokines TNF- $\alpha$ and $I L-6$ (Figure $5 b$ ), forming a vicious cycle to amplify acute inflammation.

In conclusion, Angptl2 is likely to have a significant role in inducing acute inflammation, sharing at least in part its downstream molecular signaling as involved in chronic inflammation. The current results suggest a potential validity of Angptl2 as a therapeutic target for various inflammatory diseases.

\section{ACKNOWLEDGEMENTS}

We thank Ikuyo Hirose and Shiho Namba (Hokkaido University) for technical assistance. This work was supported in part by the Takeda Science Foundation (to AK).

\section{DISCLOSURE/CONFLICT OF INTEREST}

The authors declare no conflict of interest.

1. Medzhitov R. Origin and physiological roles of inflammation. Nature 2008;454:428-435.

2. Medzhitov R. Inflammation 2010: new adventures of an old flame. Cell 2010, 140:771-776.

3. Nussenblatt RB. Uveitis in Behcet's disease. Int Rev Immunol 1997;14:67-79.

4. Mizoguchi $Y$, Sakagami $Y$, Kuboi $H$, et al. Effects of the polysaccharide chain of lipopolysaccharide in an experimental massive hepatic cell necrosis model. Biochem Biophys Res Commun 1988;155:1305-1310.

5. Noyori K, Okamoto R, Takagi T, et al. Experimental induction of arthritis in rats immunized with Escherichia coli 0:14 lipopolysaccharide. J Rheumatol 1994;21:484-488.

6. Hermida J, Montes R, Munoz MC, et al. Effects of low molecular weight heparin, alone or combined with antithrombin III, on mortality, fibrin deposits and hemostatic parameters in endotoxin-induced disseminated intravascular coagulation in rabbits. Am J Hematol 1999;60:6-11.

7. Rosenbaum JT, McDevitt HO, Guss RB, et al. Endotoxin-induced uveitis in rats as a model for human disease. Nature 1980;286:611-613.

8. Bhattacherjee P, Williams RN, Eakins KE. An evaluation of ocular inflammation following the injection of bacterial endotoxin into the rat foot pad. Invest Ophthalmol Vis Sci 1983;24:196-202.

9. Hoekzema R, Verhagen $C$, van Haren $M$, et al. Endotoxin-induced uveitis in the rat. The significance of intraocular interleukin-6. Invest Ophthalmol Vis Sci 1992;33:532-539.

10. Hafezi-Moghadam A, Noda K, Almulki L, et al. VLA-4 blockade suppresses endotoxin-induced uveitis: in vivo evidence for functional integrin up-regulation. FASEB J 2007;21:464-474.

11. Baeuerle PA, Henkel T. Function and activation of NF-kappa B in the immune system. Annu Rev Immunol 1994;12:141-179.

12. Guha M, Mackman N. LPS induction of gene expression in human monocytes. Cell Signal 2001;13:85-94.

13. Satici A, Guzey M, Gurler B, et al. Malondialdehyde and antioxidant enzyme levels in the aqueous humor of rabbits in endotoxin-induced uveitis. Eur J Ophthalmol 2003;13:779-783.

14. Baker RG, Hayden MS, Ghosh S. NF-kappaB, inflammation, and metabolic disease. Cell Metab 2011;13:11-22.

15. Baldwin Jr. AS. The NF-kappa B and I kappa B proteins: new discoveries and insights. Annu Rev Immunol 1996;14:649-683.

16. Kim I, Moon SO, Koh KN, et al. Molecular cloning, expression, and characterization of angiopoietin-related protein. angiopoietin-related protein induces endothelial cell sprouting. J Biol Chem 1999;274: 26523-26528.

17. Kubota $Y$, Oike $Y$, Satoh $S$, et al. Cooperative interaction of Angiopoietin-like proteins 1 and 2 in zebrafish vascular development. Proc Natl Acad Sci USA 2005;102:13502-13507. 
18. Tabata M, Kadomatsu T, Fukuhara S, et al. Angiopoietin-like protein 2 promotes chronic adipose tissue inflammation and obesity-related systemic insulin resistance. Cell Metab 2009;10:178-188.

19. Okada T, Tsukano H, Endo M, et al. Synoviocyte-derived angiopoietinlike protein 2 contributes to synovial chronic inflammation in rheumatoid arthritis. Am J Pathol 2010;176:2309-2319.

20. Aoi J, Endo M, Kadomatsu T, et al. Angiopoietin-like protein 2 is an important facilitator of inflammatory carcinogenesis and metastasis. Cancer Res 2011;71:7502-7512.

21. Endo M, Nakano M, Kadomatsu T, et al. Tumor cell-derived angiopoietin-like protein ANGPTL2 is a critical driver of metastasis. Cancer Res 2012;72:1784-1794.

22. Ogata A, Endo M, Aoi J, et al. The role of angiopoietin-like protein 2 in pathogenesis of dermatomyositis. Biochem Biophys Res Commun 2012;418:494-499.

23. Sun $\mathrm{H}$, Zheng JM, Chen $\mathrm{S}$, et al. Enhanced expression of ANGPTL2 in the microvascular lesions of diabetic glomerulopathy. Nephron Exp Nephrol 2007;105:e117-e123.

24. Farhat N, Thorin-Trescases N, Voghel G, et al. Stress-induced senescence predominates in endothelial cells isolated from atherosclerotic chronic smokers. Can J Physiol Pharmacol 2008;86:761-769.

25. Oike Y, Tabata M. Angiopoietin-like proteins-potential therapeutic targets for metabolic syndrome and cardiovascular disease. Circ J 2009;73:2192-2197.

26. Nagai N, Oike Y, Noda K, et al. Suppression of ocular inflammation in endotoxin-induced uveitis by blocking the angiotensin II type 1 receptor. Invest Ophthalmol Vis Sci 2005;46:2925-2931.

27. Noda K, Miyahara S, Nakazawa T, et al. Inhibition of vascular adhesion protein-1 suppresses endotoxin-induced uveitis. FASEB J 2008;22: 1094-1103.

28. Kubota $\mathrm{S}$, Kurihara $\mathrm{T}$, Mochimaru $\mathrm{H}$, et al. Prevention of ocular inflammation in endotoxin-induced uveitis with resveratrol by inhibiting oxidative damage and nuclear factor-kappaB activation. Invest Ophthalmol Vis Sci 2009;50:3512-3519.

29. Kanda A, Friedman JS, Nishiguchi KM, et al. Retinopathy mutations in the bZIP protein NRL alter phosphorylation and transcriptiona activity. Hum Mutat 2007;28:589-598.

30. Kanda A, Stambolian D, Chen W, et al. Age-related macular degeneration-associated variants at chromosome $10 \mathrm{q} 26$ do not significantly alter ARMS2 and HTRA1 transcript levels in the human retina. Mol Vis 2010;16:1317-1323.

31. Karaskov E, Scott C, Zhang $\mathrm{L}$, et al. Chronic palmitate but not oleate exposure induces endoplasmic reticulum stress, which may contribute to INS-1 pancreatic beta-cell apoptosis. Endocrinology 2006;147: 3398-3407.

32. Nakayama $\mathrm{Y}$, Endo $\mathrm{M}$, Tsukano $\mathrm{H}$, et al. Molecular mechanisms of the LPS-induced non-apoptotic ER stress-CHOP pathway. J Biochem 2010;147:471-483.

33. Fuentes ME, Durham SK, Swerdel MR, et al. Controlled recruitment of monocytes and macrophages to specific organs through transgenic expression of monocyte chemoattractant protein-1. J Immunol 1995;155:5769-5776.

34. Becker MD, Garman K, Whitcup SM, et al. Inhibition of leukocyte sticking and infiltration, but not rolling, by antibodies to ICAM-1 and LFA-1 in murine endotoxin-induced uveitis. Invest Ophthalmol Vis Sci 2001;42:2563-2566.

35. Springer TA. Signals on endothelium for lymphocyte recirculation and leukocyte emigration: the area code paradigm. Harvey Lect 1993; 89:53-103.

36. Mo JS, Matsukawa A, Ohkawara $S$, et al. Role and regulation of IL-8 and MCP-1 in LPS-induced uveitis in rabbits. Exp Eye Res 1999;68: 333-340.

37. Tuaillon N, Shen DF, Berger RB, et al. MCP-1 expression in endotoxininduced uveitis. Invest Ophthalmol Vis Sci 2002;43:1493-1498.

38. Planck SR, Huang XN, Robertson JE, et al. Cytokine mRNA levels in rat ocular tissues after systemic endotoxin treatment. Invest Ophthalmol Vis Sci 1994;35:924-930.

39. Suzuki Y, Ohgami K, Shiratori K, et al. Suppressive effects of astaxanthin against rat endotoxin-induced uveitis by inhibiting the NF-kappaB signaling pathway. Exp Eye Res 2006;82:275-281.

40. Creus KK, De Paepe B, Werbrouck BF, et al. Distribution of the NF-kappaB complex in the inflammatory exudates characterizing the idiopathic inflammatory myopathies. Ann N Y Acad Sci 2009;1173: 370-377.

41. Berti R, Williams AJ, Moffett JR, et al. Quantitative real-time RT-PCR analysis of inflammatory gene expression associated with ischemiareperfusion brain injury. J Cereb Blood Flow Metab 2002;22: 1068-1079. 